\title{
O MEC-INEP contra a Reforma Capanema: renovação do ensino secundário na década de 1950
}

\author{
Norberto Dallabrida*
}

\begin{abstract}
Resumo
Este artigo tem o intuito de compreender o modelo pedagógico renovador do ensino secundário brasileiro que foi colocado em circulação em textos publicados, na segunda metade da década de 1950, no periódico "Educação e Ciências Sociais - Boletim do Centro Brasileiro de Pesquisas Educacionais”. Considera-se que um modelo pedagógico é produzido, colocado em circulação de diversificados modos e apropriado de forma específica e inventiva. Na difusão escrita, os periódicos educativos têm um papel importante na medida em que estão vinculados a posiçóes no campo educacional. Por um lado, este artigo procura compreender a proposta renovadora de Jayme Abreu, como técnico do INEP, sobre o ensino secundário; de outra parte, explora as prescriçóes da Diretoria do Ensino Secundário do Ministério da Educação e Cultura para as classes secundárias experimentais. Numa época marcada por acirrados debates educacionais, intenta-se dar visibilidade ao modelo pedagógico renovador do ensino secundário brasileiro, que se opunha à Reforma Capanema.
\end{abstract}

Palavras-chave: Ensino Secundário. Movimento de Renovação Pedagógica. INEP.

\footnotetext{
* Doutor em História Social pela Universidade de São Paulo (USP). Professor do Curso de Pedagogia e do Programa de Pós-Graduação na Universidade do Estado de Santa Catarina (UDESC).
} 
No Brasil, durante a ditadura do Estado Novo, o ensino secundário foi reestruturado pela Reforma Capanema (1942), que lhe prescreveu uma cultura escolar marcada pelo retorno das humanidades, pela nacionalização autoritária e pela permanência do método "tradicional". Essa reforma, que fixou dois ciclos para o ensino secundário - o ginasial e o colegial -, determinou o ensino de Latim em todas as cinco séries do primeiro ciclo, diferenciando-se da Reforma Francisco Campos (1931), que previa essa língua morta somente nas duas últimas séries desse período do ensino secundário e havia tonificado as disciplinas vinculadas às Ciências Naturais. Na exposição de motivos que acompanha a Lei Orgânica do Ensino Secundário de 1942, o então ministro da Educação e Saúde, Gustavo Capanema (apud NUNES, 1962, p. 112), sublinha a importância fulcral da construção escolar da "consciência patriótica", afirmando que "o ensino secundário deve ser um ensino patriótico por excelência, e patriótico no sentido mais alto da palavra”. Não por acaso, a cultura escolar prescrita pela Lei Orgânica do Ensino Secundário foi transversalizada pelo nacionalismo estadonovista, com destaque para as disciplinas História do Brasil e Geografia do Brasil. Na estrutura escolar nacional, o ensino secundário permaneceu um reduto do tradicionalismo pedagógico, que se materializava no predomínio da aula expositiva e na segregação de gênero. A permanência dessa cultura escolar deve-se, em boa medida, ao fato de que a maioria dos colégios desse nível de ensino pertencia à Igreja Católica, que sustentou a ditadura getulista.

A partir de 1945, com o início da redemocratização da sociedade brasileira, o ensino secundário integrou a pauta das discussôes na elaboração da Lei de Diretrizes e Bases da Educação Nacional (LDBEN). De acordo com as determinaçóes da Constituição de 1946, que deu ordenamento jurídico à nova conjuntura política, o primeiro projeto da LDBEN foi apresentado no Congresso Nacional em 1948, mas logo foi arquivado. Somente dez anos depois, esse encaminhamento foi retomado no legislativo brasileiro por meio do chamado "Substitutivo Lacerda", que, ao fazer uma enfática defesa da escola privada, acirrou a divisáo do campo educacional brasileiro. O grupo que defendia o fortalecimento da escola pública era formado por boa parte de antigos pioneiros da educaçáo nacional e por novos intelectuais e políticos, que marcaram posição por meio do lançamento, em 1959, do "Manifesto dos Educadores Mais Uma Vez Convocados". A primeira Lei de Diretrizes e Bases da Educação Nacional, aprovada em 1961, estabeleceu a descentralização da educação nacional, criando os conselhos estaduais de educação e permitiu uma 
flexibilização curricular no sistema de ensino. No tocante à escolarização pósprimária, a LDBEN criou o "ensino médio", que estabeleceu a equivalência definitiva entre o ensino secundário e os cursos profissionais e o curso normal, superando, de modo legal, o histórico dualismo escolar no Brasil.

No entanto, a renovação mais efetiva do ensino secundário foi colocada em marcha, a partir da década de 1950, pelo Instituto Nacional de Estudos Pedagógicos (INEP) e pela Diretoria do Ensino Secundário do Ministério (DESE) do Ministério da Educação e Cultura. Sob a direção e liderança de Anísio Teixeira, em 1955, o INEP estabeleceu parceria com a United Nations Educational, Scientificand Cultural Organization (UNESCO), que se materializou na criação do Centro Brasileiro de Pesquisas Educacionais (CBPE), passando a realizar pesquisa científica inédita sobre o sistema escolar brasileiro com o objetivo de democratizá-lo e de modernizá-lo. O ensino primário e a formação do seu corpo docente foi a prioridade do CBPE, mas o ensino secundário também foi alvo de investigações, que resultaram na publicação de relatórios, artigos científicos e livros. De outra parte, a DESE envidou esforços no sentido de renovar a configuração do ensino secundário definida pela Lei Orgânica do Ensino Secundário, especialmente por meio da viabilização da implantação das classes secundárias experimentais. Nessa direção, o presente trabalho tem o intuito de compreender o modelo pedagógico renovador do ensino secundário brasileiro que circulou no CBPE e pela DESE entre 1956 - quando ocorreu a instalação do CBPE - e 1959 - ano da implantação das classes secundárias experimentais e da criação de estratégias de avaliação desse ensaios pedagógico.

Para compreender essa questão, utiliza-se a perspectiva historiográfica elaborada por Chartier $(1990,1992)$, que considera que os bens culturais são produzidos, colocados em circulação e usados de forma específica e inventiva, de modo que a recepção é realizada com criatividade, por meio de resistências, ressignificações e arranjos. No campo pedagógico, essa perspectiva teórica é movimentada, de forma consistente, por Carvalho (2003), que coloca o foco sobre as operaçôes de produção, de circulação e de apropriação de modelos pedagógicos, particularmente na era da "escola de massas". A circulação escrita de modelos pedagógicos, transversalizada por jogos de poder, materializa-se em textos publicados na forma de impressos como livros, artigos científicos e em projetos pedagógicos de instituiçóes escolares, entre outros. Nessa trama, os periódicos educativos têm um papel importante na medida em que fazem 
circular modelos pedagógicos em circuitos específicos, que estão conectados a posições no campo (BOURDIEU, 2003) educativo. A fonte histórica utilizada nesta investigação é o periódico "Educação e Ciências Sociais - Boletim do Centro Brasileiro de Pesquisas Educacionais" - mais conhecido como "Boletim do CBPE" -, que teve publicação quadrimensal durante o recorte temporal elegido. Trata-se do periódico oficial do Centro Brasileiro de Pesquisas Educacionais (CBPE) que tinha uma linha editorial fundamentada no discurso do grupo de educadores liderados por Anísio Teixeira, que marcava uma posição renovadora no campo educacional brasileiro.

Para estudar a circulação do modelo pedagógico renovador do ensino secundário em textos publicados no periódico "Educação e Ciências Sociais", na segunda metade da década de 1950, é importante conhecer os traços gerais da instituição e da estruturação do Centro Brasileiro de Pesquisas Educacionais. Contudo, o foco deste trabalho é colocado na análise de textos do Boletim do CBPE que problematizam o ensino secundário brasileiro a partir de diversificados aspectos e à luz de experiências internacionais e/ou propóem novos formatos pedagógicos desse nível de escolarização.

\section{Uma proposta inepiana para o ensino secundário}

Durante a sua gestão à frente do INEP, Anísio Teixeira priorizou a investigação científica do sistema nacional de ensino. Em 1952, logo após assumir a direção do Instituto Nacional de Estudos Pedagógicos, Anísio Teixeira criou a Campanha do Livro Didático e Manuais de Ensino (CALDEME) e, no ano seguinte, a Campanha de Inquéritos e Levantamentos do Ensino Médio e Elementar (CILENE), que tinha o intuito de fazer investigaçôes científicas acerca da educação nacional (LEITE FILHO; SANTOS; GOUVÊIA, 2008). A partir de 1955, o CBPE, com sede na capital da República, e os seus Centros Regionais de Pesquisas Educacionais (CRPEs), localizados nas cidades de Recife, Salvador, Belo Horizonte, São Paulo e Porto Alegre, incorporaram as atividades da CALDEME e CILENE (ARAÚJO; GATTI JÚNIOR, 2006; LUGLI, 2002). De acordo com o artigo $2^{\circ}$ do Decreto $n^{\circ} 38.460$, de 28 de dezembro de 1955 , que instituiu o CBPE, os objetivos desse órgão são os seguintes:

I - pesquisa das condiçôes culturais e escolares e das tendências de desenvolvimento de cada regiáo e da sociedade brasileira como um todo, para o efeito de 
elaboração gradual de uma política educacional para o país;

II - elaboração de planos, recomendaçóes e sugestóes para a revisão e a reconstrução educacional do país - em cada regiấo - nos níveis primário, médio e superior e no setor de educaçáo de adulto;

III - elaboraçáo de livros de fontes e de textos, de material de ensino e estudos especiais, sobre administração escolar, construção de currículos, psicologia educacional, filosofia da educação, medidas escolares, preparo de mestres, etc., a fim de propiciar o aperfeiçoamento do magistério nacional;

IV - treinamento e aperfeiçoamento de administradores escolares, orientadores educacionais, especialistas em educação, professores de escolas normais e professores primários. (BRASIL, 1955).

A criação do CBPE e de seus cinco centros regionais de pesquisa educacional foi o empreendimento estratégico liderado por Anísio Teixeira para reinventar o INEP com o intuito de alavancar o "Programa de Reconstrução Educacional". Assim, por meio da instituição do CBPE e dos CRPEs, é retomada a ideia da constituição de um sistema nacional de ensino que havia sido enunciado no "Manifesto dos Pioneiros da Educação Nova" e suspensa durante o Estado Novo - período marcado pelas leis orgânicas do ensino, de autoria do entáo ministro da Educação e Saúde Gustavo Capanema (XAVIER, 1999). De outra parte, há uma sinalização da descentralização da educação com a criação de instâncias regionais, mas integradas à coordenação nacional. Ademais, na sua introduçáo, o Decreto n 38.460 afirma que a principal meta dos centros brasileiros e regionais de pesquisas educacionais é o "estudo e aperfeiçoamento do magistério brasileiro, primário e normal” (BRASIL, 1955), sinalizando a eleição do curso primário entre os diversos níveis da escolarização brasileira. Dessa forma, o Centro Brasileiro de Pesquisas Educacionais consolidou-se como um órgáo do MEC/INEP marcado por iniciativas dinâmicas na área de pesquisa educacional e atualização docente por meio de congressos e cursos, conectados em nível internacional, particularmente com a UNESCO.

Desde a sua concepção o Centro Brasileiro de Pesquisas Educacionais priorizou, nas suas pesquisas científicas e nos seus treinamentos, a formação de professores para o ensino primário. No entanto, embora não colocado em 
primeiro plano, o ensino secundário também foi alvo de investigaçôes científicas e de debates tanto no CBPE como nos CRPEs. Segundo Mendonça e Xavier (2008, p. 32), "para Anísio Teixeira, a questão do ensino médio era o verdadeiro nó do sistema educacional brasileiro e uma das suas principais bandeiras era integrá-lo ao ensino primário". A questão da equiparação entre os dois ciclos do ensino secundário e os dois ciclos do ensino comercial, industrial, agrícola e normal também foi objeto de preocupação da equipe de pesquisadores CBPE, que teria solução definitiva somente na Lei de Diretrizes e Bases da Educação Nacional de 1961. No Centro Brasileiro de Estudos Educacionais ganharam destaque as análises de Jayme Abreu - técnico muito próximo a Anísio Teixeira -, que coordenou a Campanha de Inquéritos e Levantamentos do Ensino Médio e Elementar (CILENE) e atuou, na linha de frente do INEP, até meados dos anos 1960 (SOUZA, 2008). Sobre o ensino secundário, ele publicou artigos em periódicos científicos e o livro "A escola secundária no Brasil" (ABREU, 1955), fruto de um estudo apresentado no "Seminário Interamericano de Educação Secundária", realizado em 1955, em Santiago do Chile (BERETA; DALLABRIDA; CLARINO, 2013).

No "Boletim do CBPE", Abreu (1957) publicou um artigo em que faz consideraçóes e propóe um substitutivo ao Projeto 4.132 C., que apresenta novo texto à Lei Orgânica do Ensino Secundário, de autoria de Nestor Jost, que tramitava no Senado Federal. Esse artigo explicita a postura do Centro Brasileiro de Pesquisas Educacionais na discussão do ensino secundário em curso na década de 1950 a partir da pena de um de seus mais competentes representantes. A primeira observação do texto de Abreu (1957) é sobre a conveniência do "legislar parcial e fragmentário" ao modo das leis orgânicas do ensino aprovadas durante o Estado Novo. Critica abertamente esse encaminhamento jurídico porque estava na contramão do "planejamento global do problema educacional brasileiro", já anunciado no "Manifesto dos Pioneiros da Educaçáo Nova", no início dos anos 1930. Assim, defendendo a proposta da LDBEN do Ministério da Educação e Cultura, afirma: "Um dos fundamentos mais sólidos da justificação do anteprojeto de lei de Diretrizes e Bases da Educaçáo Nacional era, ao nosso ver, a consideração da "oportunidade que se abre para um sistema contínuo e articulação de educação para todas as classes, desde o ensino infantil até o superior" (ABREU, 1957, p. 233). A posição do CBPE anisiano foi contrária ao fatiamento da legislação educacional brasileira de corte estadonovista, defendendo um sistema de ensino nacional orgânico e articulado. 
A outra observação de Jayme Abreu sobre o Projeto 4.132 C., considerado conservador, concentra-se na defesa da descentralização da educação nacional. Também nesse ponto trata-se de um ataque à Reforma Capanema, que enquadrou o ensino secundário numa forma nacional rígida, desconsiderando a diversidade do Brasil e dos indivíduos. A defesa da descentralização da educação nacional estava afinada com a postura de Anísio Teixeira, que fez formação nos Estados Unidos da América e, de acordo com a regionalizaçáo colocada em marcha pelo CBPE, tinha cinco centros regionais de pesquisa educacionais. Aceitando a proposta da LDBEN proposta pelo Ministério da Educaçáo e Cultura, Abreu (1957, p. 239) faz defesa aguerrida da descentralização da educação nacional, ao concluir:

Ao assim nos definirmos, pela continuidade da política descentralizadora da educação esposada pelo Ministério da Educação, alicerça-nos a convicção, ainda não superada, de que a descentralização do ensino sobre ser princípio normativo de nossa constituição de república federativa, como um corolário mesmo da extensão e variedade do país, não o é menos, por definiçấo, conhecimento básico do processo educativo, insusceptível de rígida e uniforme padronização legal.

A nosso ver, é preciso chegar-se não apenas ao equivocado gosto da palavra, mas a uma efetiva atitude de descentralização de responsabilidades, pois nenhuma falácia é mais perigosa no processo educativo do que admitir-se a viabilidade da chamada 'centralização de fins com descentralização de meios', com cérebros federais que pensam e programas à distância e braços estaduais, automatizados, que executam.

A posição do CBPE no texto de Jayme Abreu (1957) explicita-se ainda mais na apresentação de um substitutivo ao Projeto 4.132 C., apoiado na proposta de Lei de Diretrizes e Bases da Educação Nacional. Em primeiro lugar, o que chama a atenção é a formulação do conceito de "educação de nível médio", que integrava o ensino secundário e os cursos profissionais, estabelecendo a equivalência formal e completa entre os diferentes ramos do ensino pós- 
primário. Essa posição contrastava com as leis orgânicas aprovadas pela Reforma Capanema, que tratava separadamente tanto o ensino secundário como os cursos profissionais. Em segundo lugar, o substitutivo Jayme Abreu (1957, p. 240) faz uma defesa da "democratização quantitativa" do ensino médio, quando afirma: "Art. 3 - A educação de nível médio deverá estender-se progressivamente a todos os adolescentes, oferecendo iguais e variadas oportunidades ao desenvolvimento de suas possibilidades individuais específicas". Essa postura democrática também está em oposição à Lei Orgânica do Ensino Secundário, elaborada por Gustavo Capanema, que afirmava que o ensino secundário deveria produzir as "individualidades condutoras". Na década de 1950, o ensino secundário, dominado por colégios privados, ainda era muito elitizado e o CBPE fazia uma aberta defesa da sua universalização.

Em terceiro lugar, a legislação educacional proposta por Abreu mantém os sete anos que compunham o ensino secundário ou os cursos profissionais, mas faz uma reestruturação de ciclos e de cursos da "educação de nível médio". Frente aos dois ciclos rígidos da Reforma Capanema, é proposta a criação de três ciclos, respectivamente, de dois, de três e de dois anos. Os dois primeiros ciclos são chamados de "ginásio", sendo que o primeiro deve articular os ensinos primário e médio, podendo funcionar em escolas primárias, e o segundo deveria dar continuidade ao ciclo anterior e proporcionar iniciação profissional. O terceiro ciclo, denominado "colégio", é diversificado de acordo com os ramos secundário, comercial, industrial, agrícola e outros a serem criados. O Curso Secundário prevê no segundo ciclo cursos paralelos, diferenciados na ênfase na cultura geral ou nas atividades profissionais; no último ciclo deveria ter quatro cursos paralelos: geral, letras clássicas, letras modernas e ciências (ABREU, 1957).

Além dessa maior diversificação no terceiro ciclo, o Substitutivo Jayme Abreu previa também estímulo da União para a criação de conselhos locais de educação e a elaboração de planos estaduais e municipais de educaçáo, bem como previa que o Conselho Nacional de Educação poderia permitir a realização de experiências pedagógicas não previstas em lei, apostando na descentralização e flexibilização do ensino médio. Ademais, garantia o direito de fazer inscrição em concursos para o ingresso no ensino superior para quem concluísse o último ciclo da "educação em nível médio" (ABREU, 1957, p. 248-249). Em boa medida, essa configuração do ensino médio brasileiro seria contemplada na LDBEN de 1961. 


\section{As prescrições para as classes secundárias experimentais}

A introdução das classes experimentais no ensino secundário brasileiro foi recomendada pela Primeira Jornada de Estudos de Diretores de Estabelecimentos de Ensino Secundário, que se realizou, em 1957, na cidade de São Paulo. Essa sugestão foi objeto de discussão na V Reunião de Inspetores Seccionais, que a acatou por unanimidade. Dessa forma, o titular da Diretoria do Ensino Secundário (DESE) do Ministério da Educação e Cultura, Gildásio Amado (1958), solicitou parecer sobre essa matéria ao técnico em educação do órgão que ele dirigia, Adalberto Correia Sena. No seu parecer, exarado em 31 de janeiro de 1958, Sena (1958, p. 78-79) argumentou que o regime de equivalência entre o ensino secundário e os cursos profissionais e normal estabelecida pela Lei n. 1.821, de 12 de março 1953, permitia a flexibilização da Lei Orgânica do Ensino Secundário, viabilizando, legalmente, a implantação legal das classes experimentais no ensino secundário. Diante da uniformidade estabelecida pela Reforma Capanema, o técnico da DESE recomendava a permissão de "ensaios de ensino diversificado", mas sugere estudos preparatórios na implantação da experiência renovadora das classes experimentais no ensino secundário, bem como uma "regulamentação prudente". O parecer do técnico Adalberto Correia Sena converteu-se na peça jurídica fundamental para a DESE dar os encaminhamentos cabíveis junto ao Governo Federal no sentido de permitir a implantação das classes secundárias experimentais.

Em 14 de fevereiro de 1958, o Diretor do Ensino Secundário, Gildásio Amado (1958), enviou uma "Exposiçẫo de Motivos" ao Ministério da Educação e Cultura, tendo em anexo o projeto de decreto que permitia o estabelecimento de classes experimentais no ensino secundário. O titular da DEPE inicia o texto afirmando que a criação das classes experimentais vem sendo solicitada pelos educadores brasileiros com o intuito de efetivar uma maior diversificação do ensino secundário. Diz também que a flexibilização da cultura escolar do ensino secundário está prevista no projeto da Lei de Diretrizes e Bases da Educação Nacional, em discussão no Congresso Nacional por meio da ramificação dos cursos ginasial e colegial e na forma de disciplinas optativas. E arrola uma série de "característica principais" e "normais gerais" que deveriam ter as classes experimentais secundárias, que, em boa medida, foram incorporadas à legislação que lhes deu legalidade no início do ano seguinte. Fundamentado no parecer de Adalberto Correia Sena, Amado (1958, p. 74) procura sublinhar a legalidade da 
cultura escolar renovadora proposta para o ensino secundário, asseverando: “ $\mathrm{O}$ caráter de experiência que tem a medida proposta seria suficiente para justificála, não fosse o fundamento legal que a lei oferece. Realmente, a Lei n. 1.821, de 12 de março de 1953, que instituiu o regime de equivalência dos cursos, consagrou o princípio de variação do ensino". Nesse sentido, de acordo com a legislação então em vigor, as classes experimentais secundárias eram consideradas equivalentes aos cursos da escolarização média no Brasil.

Ao final da sua "Exposição de Motivos", Amado (1958) sugere que a implantação das classes experimentais na escolarização média brasileira seja apreciada pelo Conselho Nacional de Educação, o que de fato ocorreu. Na Comissão de Ensino Secundário, a proposta da DEPE foi apreciada por Celso Kelly, levando em conta duas questôes. Por um lado, a existência de ginásios e colégios de aplicação nas Faculdades de Filosofia, que devem colocar em prática experiência renovadoras de ensino. De outra parte, ratificou o caráter legal da instalação das classes experimentais no ensino secundário, baseado na Lei $n^{\circ} 1.821$ (BRASIL, 1953), que estabelece a equivalência entre as diversas modalidades de cursos da escolarização média. O parecer de Kelly (1958) foi favorável às classes experimentais secundárias, sendo aprovado pelo Conselho Nacional de Educação sob o número 31/58. Baseado nesse documento e no parecer $\mathrm{n}^{\circ} 77 / 58$, da Consultoria Jurídica do Ministério da Educação, por meio da Circular N. 1, de 4 de julho de 1958, a Diretoria do Ensino Secundário estabeleceu as "Instruçóes sobre a natureza e a organização das classes experimentais" (BRASIL, 1958), que prescreviam a cultura escolar para essas turmas renovadoras do ensino secundário.

Com o desiderato de ensaiar novos métodos de ensino e processos escolares, as "Instruções sobre a natureza e a organização das classes experimentais" autorizavam a instalação de classes experimentais nos cursos ginasial e colegial - ou seja, nos dois ciclos do ensino secundário - a partir do ano de 1959. Essa norma afirma que procura viabilizar um clamor dos educadores em prol da "diversificação do ensino secundário", que em boa medida vem sendo prevista na Lei de Diretrizes e Bases da Educação Nacional, que estava em debate no Congresso Nacional. O seu item 3 estabelece "características das classes experimentais" (BRASIL, 1958) determinando que, prioritariamente, essas classes deveriam ser implantadas no primeiro ciclo do ensino secundário, ou seja, no curso ginasial; em um número reduzido de classes, iniciando na primeira e, mediante avaliação, poderia ser expandida para as outras classes do 
ginásio; e em "colégios de idoneidade incontestável e de condiçóes pedagógicas que possibilitem a experiência" (BRASIL, 1958, p, 80), devendo ter precedência o Colégio Pedro II e os colégios de aplicaçóes das Faculdades de Filosofia. Esses aspectos indicam a preocupaçáo do Ministério da Educação e Cultura em não permitir o excesso de experimentalismo, garantindo o caráter de ensaio das classes secundárias experimentais.

Para tanto, as "Instruçôes sobre a natureza e a organização das classes experimentais" estabeleciam estritos mecanismos de controle do Ministério da Educação e Cultura por meio da necessidade da prévia autorização e da "assistência especial" da DESE e o credenciamento dos professores, bem como o "prévio consentimento dos pais ou responsáveis dos alunos matriculados" (BRASIL, 1958, p. 80). E elas determinavam as seguintes "normais gerais" para a organização das classes experimentais:

a) na organização dos currículos, ter-se-á em vista não a especialização nesta ou naquela direção de estudos, mas na preparação geral com um sólido conteúdo de formação humana e maiores oportunidades de atendimento das aptidóes individuais;

b) maior articulação do ensino das várias disciplinas e maior coordenação das atividades escolares;

c) número máximo de trinta alunos em cada classe, para que o ensino se possa adaptar melhor a cada aluno;

d) o número de professores nas classes iniciais do ginásio poderá ser reduzido para evitar os inconvenientes da transição brusca do regime primário para o secundário. Os professores terão, assim, convívio mais demorado com os alunos, podendo melhor examinar-lhes as tendências e exercerem uma orientação eficiente;

e) reuniôes periódicas dos professores de cada classe para a apreciação da classe nos seus aspectos psicológicos e sua melhor e mais homogênea orientação pedagógica;

f) possibilidade de opçôes que correspondem às aptidôes dos alunos;

g) acentuação da função educativa da escola de maior permanência diária na escola e de participação nas atividades extracurriculares; 
h) atividade dirigida, planejada de modo que o aluno dela possa participar ativamente, para adquirir seu método próprio de trabalho e hábitos de vida conscientes e dinâmicas;

i) articulação mais estreita entre professores e pais, tão necessária para a harmonia que deve existir entre a obra educadora da escola e da família. (BRASIL, 1958, p. 80-81).

Essa normatização revela a prescrição de uma cultura escolar renovadora para o ensino secundário. Por um lado, expressa uma preocupação com o desenvolvimento das "aptidôes individuais" dos alunos, que se efetivavam na limitação de até trinta alunos e na possibilidade de os discentes optarem por disciplinas e atividades educativas. Trata-se de uma perspectiva psicologizante de corte escolanovista, que se articulava a outra condição sine qua non para o funcionamento das classes secundárias experimentais, qual seja: a existência do Serviço de Orientação Educacional. Por outro lado, estipula exigência em relação ao corpo docente, que deveria ter reuniôes regulares, sendo agrupado por classes, particularmente para viabilizar a articulação de várias "disciplinassaber". Para os docentes das classes iniciais do curso ginasial, indicava a existência de um número reduzido de professores com o objetivo de evitar a passagem pereptória do ensino primário unidocente para o ensino secundário pluridocente. Ademais, as "normas gerais" manifestam uma preocupação com a articulaçáo entre escola e família, de sorte que a afinar os fins educativos dessas duas instituiçóes sociais. Assim, elas estabeleciam uma cultura escolar contrastante em relação às prescriçôes da Reforma Capanema.

A solicitação de funcionamento das classes experimentais no ensino secundário deveria ser feita até o último dia de agosto de cada ano à Inspetoria Secional do Ensino Secundário, que era vinculada à DESE, e conter um plano quadrianual, ou seja, um planejamento inicialmente previsto para a implantação das classes experimentais nos quatro anos do curso ginasial. Nesse plano, elaborado por uma comissáo formada pelo diretor do colégio e por dois professores, deveriam ser explicitados os "objetivos da experiência, sua fundamentação, conveniência, exequibilidade e demonstração da impossibilidade de realiza-la dentro do regime normal de funcionamento do curso ginasial ou colegial" (BRASIL, 1958, p. 82) e uma série de itens pedagógicos tais como currículo, horário, organização do corpo docente, 
métodos e processos de ensino, orientação educacional, atendimento a diferenças individuais, aferição final dos resultados da experiência, entre outros. $\mathrm{O}$ monitoramento da experiência das classes secundárias experimentais era previsto, materializando-se por meio do envio de um relatório anual à DESE, incluindo as modificaçóes efetivadas em relação ao plano quadrianual, e a designação, pela DESE, de um educador-supervisor em cada estabelecimento de ensino. Enfim, as "Instruçôes sobre a natureza e a organização das classes experimentais" definiram prescrições objetivas operacionais para garantir uma implantação gradual e segura das classes secundárias experimentais, evitando a disseminação indiscriminada desses ensaios educativos.

A implantação das classes secundárias experimentais foi autorizada pela Portaria $n^{\circ} 1$, de 2 de janeiro de 1959, do Ministério da Educação e Cultura (ABREU; CUNHA, 1963) com o desiderato de diversificar o ensino secundário, tendo como referência pedagógica as classes nouvelles francesas ${ }^{1}$ (VIEIRA; DALLABRIDA; STEINDEL, 2013). Em meados desse ano, o CBPE se propôs a avaliar regularmente as classes secundárias experimentais implantadas, tendo a seguinte metodologia: "Serão estudados criticamente os planos apresentados pelas escolas e realizada observaçáo pessoal direta do funcionamento das classes, bem como realizadas entrevistas com roteiro pré-estabelecido e aplicados questionários (diretores, professores, alunos, etc.)" (CLASSES..., 1959, p. 126). Os coordenadores foram regionalizados, de modo que Jayme Abreu ficou encarregado de avaliar as classes dos estados de São Paulo - unidade da federação brasileira que tinha maior número de experiências - e do Rio Grande do Sul, enquanto Geraldo Bastos Silva teve ao seu encargo os estados do Rio de Janeiro, Minas Gerais e Ceará. Os tópicos que deveriam constar nos relatórios desses avaliadores, sugerem a profundidade do trabalho pesquisa. Os tópicos são os seguintes:

1 - Caracterização da organização, objetivos e clientela da escola secundária brasileira (Reforma Rocha Vaz, Francisco de Campos e Gustavo Capanema).

2 - Breve caracterização das "Classes Nouvelles" na França. A escola secundária norte-americana - A escola secundária inglesa.

3 - Origens legais das classes secundárias experimentais no Brasil. A iniciativa da Diretoria do Ensino Secundário. A posiçáo jurídica e pedagógica do Ministério da Educação e Cultura. 
4 - Características básicas, legais da organização das classes secundárias experimentais em São Paulo, Distrito Federal, Rio de Janeiro, Minas Gerais e Ceará.

5 - Filosofia educacional subjacente às iniciativas. Currículos. Programas. Métodos e Técnicas. Instalaçóes e equipamento. A clientela escolar. Direção. Discência e assistência à experiência. Previsão. Custo de sua manutenção.

6 - As diretrizes educacionais prevalecentes na experimentação em curso. Pontos de semelhança e dissemelhança. Perspectivas da experiência em relação à educação nacional. Seus pontos fortes e fracos. Adequação à conjuntura educacional brasileira. (CLASSES..., 1959, p. 126).

Levando em conta as ferramentas sofisticadas e diversificadas de análise e os pontos que deveriam constar dos relatórios dos avaliadores, constata-se que a pesquisa planejada pelo CBPE era abrangente e consistente. As dimensóes levantadas eram de ordem histórica, internacional e jurídica, mas colocava o foco sobre a filosofia educacional, o currículo em ação, os métodos, as técnicas e a clientela das experiências das classes experimentais. Tratava-se de uma proposta que realizava uma radiografia fundamentada e detalhada, que tinha o intuito de compreender as experiências inovadoras do ensino secundário brasileiro, mas também de colocar em relevo o modelo tradicional plasmado pela Reforma Capanema, que estava sendo problematizado pelo projeto da Lei de Diretrizes e Bases da Educação Nacional, que tramitava, de forma intermitente, no Congresso Nacional, bem como pelo INEP/CBPE.

Depois de aprovada a LDBEN, que descentralizou e flexibilizou o currículo do ensino secundário e o ensaio das classes experimentais ter fechado o ciclo de quatro anos do curso ginasial, Anísio Teixeira (apud ABREU; CUNHA, 1963, p. 90) anotou: "A iniciativa da criaçáo das 'classes secundárias experimentais' no sistema nacional de ensino secundário representou um esforço engenhoso da administração escolar para renovar o ensino, despeito da legislaçáo uniforme e imprópria que o disciplinava". O ainda diretor do INEP aplaudiu a experiência das classes experimentais no ensino secundário, que contribuíram, de forma acutilante, para a sua renovação pedagógica. 


\section{Considerações finais}

No quadro de técnicos do CBPE, o principal pesquisador do ensino secundário foi Jayme Abreu, autor de livro e de diversos artigos sobre esse tema publicados em diversos periódicos científicos. $\mathrm{O}$ artigo de sua autoria publicado no Boletim do CBPE sobre o projeto de Lei no 4.132 C., que estava em discussão no Senado Federal, em meados dos anos 1950, expressa a posição do INEP/CBPE em favor da renovação do ensino secundário. Em primeiro lugar, defendia a concepção de "educação de nível médio" que superasse o dualismo histórico no Brasil entre o ensino secundário elitizado e os cursos profissionais para as classes populares e partes das classes médias. Em segundo lugar, tinha uma posição francamente favorável à expansão da escolarização média, de sorte que ela atingisse as classes desfavorecidas. Por fim, apresentava uma reestruturação dos ciclos do ensino secundário, de modo que ela favorecesse maior diversificação, especialmente nos cursos terminais, quebrando o foco na preparação estrita para o ingresso no ensino superior. A proposta inepiana de Jayme Abreu, portanto, mantinha posição contrária a Lei Orgânica do Ensino Secundário, particularmente por integrar leis educacionais parciais, bem como pelo seu formato "tradicional" e caráter elitista, e mostrava-se afinada como o projeto da Lei de Diretrizes e Bases de Educação Nacional que tramitava no Congresso Nacional.

Contudo, a faceta ainda mais renovadora do ensino secundário, no Brasil, nos "anos dourados", foi efetivada por meio das classes secundárias experimentais, cuja prescrição pedagógica circulou, de forma oportuna e fluente, no Boletim do CBPE. Essas classes de ensaio tiveram como principal referência internacional as classes nouvelles francesas, que se inscreviam no movimento escolanovista, converteram-se em experiências contrastantes em relação ao formato do ensino secundário definido pela Reforma Capanema. Dessa forma, entre os seus principais traços pode-se destacar o respeito às aptidóes individuais que, em boa medida, era articulado pelo Serviço de Orientação Educacional, uso de métodos ativos, o regime de autodisciplina, constituição de turmas de no máximo trinta alunos, estímulo à integração de "disciplinas-saber" em eixos temáticos, maior permanência dos estudantes na escola por meio do oferecimento de atividades extra sala de aula e diálogo entre a família e a escola. $\mathrm{Na}$ medida em que prescreveu a descentralização do sistema de ensino brasileiro e a flexibilização curricular, a Lei de Diretrizes e Bases da Educação Nacional 
apropriou-se, parcialmente, do legado das classes secundárias experimentais, que, atualmente, é retomado no Ensino Médio Inovador.

A experiência das classes secundárias experimentais merece estudos mais aprofundados e detalhados pela historiografia da educação brasileira, procurando compreender as apropriaçóes feitas em diferentes estados da federaçáo brasileira, bem como em cada estabelecimento de ensino. Nos 50 e 60 do século XX, quando os laços internacionais se intensificavam e o mundo capitalista era vincado pela hegemonia norte-americana, as classes secundárias experimentais em movimento nos educandários privados ou colégios públicos não tiveram como referência somente as classes nouvelles franceses, mas usaram outras matrizes escolanovistas, particularmente aquelas estadudinenses, que certamente compunham ecletismos pedagógicos instigantes para a pesquisa histórica e importantes para a reinvenção da configuração atual do ensino médio.

\section{Nota}

${ }^{1}$ As classes nouvelles foram concebidas e implantadas no ensino secundário francês a partir da segunda metade da década de 1940, pelo educador Gustave Monod. Inspiradas em ideias escolanovistas e, particularmente, no Plano Langevin-Wallon, essas classes tinham até 25 alunos e número reduzido de professores com a turma ao longo dos anos, usavam métodos ativos, personalizados e cooperativos, bem como entrelaçavam trabalho manual e intelectual (ARAÚJO, 2013).

\section{REFERÊNCIAS}

ABREU, Jayme. A escola secundária no Brasil. Rio de Janeiro: MEC/Inep/ CBPE/CILEME, 1955.

ABREU, Jayme. Observaçóes preliminares a respeito do projeto $4.132 \mathrm{C}$., que dá novo texto à Lei Orgânica do Ensino Secundário Brasileiro. Educação e Ciências Sociais: Boletim do Centro Brasileiro de Pesquisas Educacionais, Rio de Janeiro, n. 5, v. 2, p. 233-255, ago. 1957.

ABREU, Jayme; CUNHA, Nádia. Classes Secundárias Experimentais: balanço de uma experiência. Revista Brasileira de Estudos Pedagógicos, Rio de Janeiro, v. 15, n. 91, p. 90-151, 1963. 
AMADO, Gildásio. Exposição de motivos do diretor do ensino secundário ao Sr. Ministro da Educação e Cultura. Revista Brasileira de Estudos Pedagógicos, Rio de Janeiro, v. 30, n.72, p. 73-78, dez. 1958.

ARAÚJO, Elisabete Maria de. Gustave Monod e as classes nouvelles: apropriaçôes e renovaçôes no ensino secundário francês. In: COLÓQUIO "ENSINO MÉDIO, HISTÓRIA, E CIDADANIA", 8., 2013, Florianópolis. Anais Eletrônicos... Florianópolis, SC: UDESC, 2013.

ARAÚJO, José Carlos Souza; GATTI JÚNIOR, Décio. O ensino baseado empesquisas e estudos como diretriz do Centro Regional de Pesquisas Educacionaisde Minas Gerais. In: ARAÚJO, Marta Maria de; BRZEZINSKI, Iria (Org.). Anísio Teixeira na direção do INEP: Programa para a Reconstrução da NaçãoBrasileira (1952-1964). Brasília: Inep, 2006. p.113-141.

BERETA, Cristiani; DALLABRIDA, Norberto; CLARINO, Juliana Maués. Ensino Secundário/Ensino Médio: a perspectiva de Jayme Abreu sobre a reforma do ensino secundário no contexto do CBPE entre 1955 e 1964. In: COLÓQUIO "ENSINO MÉDIO, HISTÓRIA, E CIDADANIA", 8., 2013, Florianópolis. Anais Eletrônicos... Florianópolis, SC: UDESC, 2013. Disponível em: <http://www.revistas.udesc.br/index.php/EnsinoMedio/ article/view/3911/2724>. Acesso em: 2 dez. 2013.

BOURDIEU, Pierre. Alta Costura e Alta Cultura. In: BOURDIEU, Pierre. Questóes de Sociologia. Tradução de Miguel Serras Pereira. Lisboa: Fim de Século, 2003. p. 205-215.

BRASIL. Lei n ${ }^{\circ} 1821$, de 12 de março de 1953. Dispóe sobre o regime de equivalência entre diversos cursos de graus médio para efeito de matrícula no cíclo colegial e nos cursos superiores. Diário Oficial da União, Rio de Janeiro, 16 mar. 1953.

BRASIL. Decreto ${ }^{\circ}$ 38.460, de 28 de dezembro de 1955. Institui o Centro Brasileirode Pesquisas Educacionais e centros regionais. Diário Oficial da Uniāo, Rio de Janeiro, 29 dez. 1955. Disponível em:<http://www2.camara. gov.br/legin/fed/decret/1950-1959/decreto-3846028dezembro-1955334313-publicacaooriginal-1-pe.html>. Acesso em: 6 jul. 2012. 
BRASIL. Ministério da Educação e Cultura. Diretoria do Ensino Secudário. Instruções sobre a natureza e a organização das classes experimentais. Revista Brasileira de Estudos Pedagógicos. Rio de Janeiro, v. 30, n. 72, p. 79-83, dez. 1958.

CARVALHO, Marta Maria Chagas de Carvalho. A Escola e A República e outros ensaios. Bragança Paulista: EDUSF, 2003. (Estudos CDAPF. Série Historiografia).

CHARTIER, Roger.A história cultural: entre práticas e representaçóes. Lisboa, DIFEL, 1990.

CHARTIER, Roger. VI. Textos, impressóes, leituras. In: HUNT, Lynn (Org.). A nova história cultural. São Paulo: Martins Fontes, 1992. p.211-238.

CLASSES secundárias experimentais. Educação e Ciências Sociais - Boletim do Centro Brasileiro de Pesquisas Educacionais, Rio de Janeiro, n. 11, v. 5 , p. 124-126, ago. 1959.

KELLY, Celso. Parecer N. 31. Rio de Janeiro, 24. fev.1958.

LEITE FILHO, Aristeo; SANTOS, Pablo S. M. B.; GOUVÊIA, Fernando. Quando os documentos falam ...ouve-se até o silêncio: entrerelatórios, decretos e manuscritos, a gestão de Anísio Teixeira no Inep/CBPE (19521964). In: MENDONÇA, Ana Waleska; XAVIER, LibâniaNacif (Org.). Por uma politica de formaçâo do magistério nacional: o Inep/MEC dos anos1950/1960. Brasília: Inep, DF, 2008. p. 39-59.

LUGLI, Rosario S. Genta.O trabalho docente no Brasil: o discurso dos centros regionais de pesquisa educacional e das entidades representativas do magistério (1950-1971). 2002. Tese (Doutorado em Educação) Universidade de São Paulo, São Paulo, 2002.

MENDONÇA, Ana Waleska P. C.; XAVIER, Libânia Nacif. O Inep no contexto das políticas do MEC (1950/1960)", In: MENDONÇA, Ana Waleska P. C.; XAVIER, Libânia Nacif (Org.). Por uma politica de formação do magistério nacional: o Inep/MEC dos anos 1950/1960. Brasília: Inep, 2008. p.19-38. (Coleção Inep 70 anos, n. 1).

NUNES, Maria Thetis. Ensino Secundário e Sociedade Brasileira. Rio de Janeiro: Instituto Superior de Estudos Brasileiros, 1962. 
SENA, Adalberto Correia. Parecer. Revista Brasileira de Estudos Pedagógicos. Rio de Janeiro, v. 30, n. 72, p. 78-79, dez. 1958.

SOUZA, Rosa Fátima de. História da organização do trabalho escolar e docurrículo no século XX: (ensino primário e secundário no Brasil). Sáo Paulo: Cortez, 2008.

VIEIRA, Letícia; DALLABRIDA, Norberto; STEINDEL, Gisela. Uma análise acerca das classes experimentais do ensino secundário paulista (19551964). COLÓQUIO "ENSINO MÉDIO, HISTÓRIA, E CIDADANIA", 8., 2013, Florianópolis. Anais Eletrônicos... Florianópolis, SC: UDESC, 2013. Disponível em: <http://www.revistas.udesc.br/index.php/ EnsinoMedio/article/view/3911/2724>. Acesso em: 2 dez. 2013

XAVIER, Libânia Nacif. O Brasil como laboratório: educação e ciências sociais no Projeto dos Centros Brasileiros de Pesquisas EducacionaisCBPE/ INEP/MEC (1950-1960). Bragança Paulista, SP: UDUSF, 1999.

XAVIER, Libânia Nacif. Qualificação de professores em três campanhas doMinistério da Educação no decênio 1950-1960. In: MENDONÇA, Ana Waleska; XAVIER, Libânia Nacif (Org.). Por uma politica de formaçấo do magistério nacional: o Inep/MEC dos anos 1950/1960. Brasília: Inep, 2008. p.127-143. 


\section{EIMEC-INEP contra la Reforma Capanema: renovación de la enseñanza secundaria en la década de 1950}

\section{Resumen}

Este artículo tiene como objetivo comprender el modelo pedagógico renovador de la enseñanza secundaria brasileña que comenzó a tener circulación en los textos publicados en la revista "Educación y Ciencias Sociales - Boletín del Centro Brasileño para la Investigación Educativa” en la segunda mitad de la década de 1950. Considera que un modelo pedagógico es producido y puesto en circulación de modos diversificados y apropiado de manera específica y creativa. En la difusión escrita, las revistas educativas tienen un papel importante porque están vinculados a las posiciones en el campo educativo. Por un lado, el artículo trata de comprender la propuesta renovadora de Jayme Abreu como experto del INEP sobre la enseñanza secundaria; por otro lado, explora las prescripciones de la Junta de Educación Secundaria del Ministerio de Educación y Cultura para las clases secundarias experimentales. En una época marcada por fuertes $y$ expresivos debates educativos, se intenta dar visibilidad a un modelo pedagógico renovador de la enseńanza secundaria en Brasil, que se oponía a la Reforma Capanema.

Palabras claves: Enseñanza Secundaria. Movimiento de Renovación pedagógica. INEP.
The MEC-INEP against Capanema Reform: renewal of the secondary education in 1950s

\section{Abstract}

This article aimes to understand the renewing pedagogical model of the brazilian secondary education that was put into circulation in published texts, on the second half of the 1950s, on the newspaper "Education and Social Sciences - Report from the Brazilian Center for Educational Research". It considers that a pedagogical model is produced, put into circulation in a variety of ways and adapted in a specific and inventive way. On the writing circulation, the educational newspapers have an important role as they are related to positions on the educational field. At one side, the article seeks to understand the renewing intention from Jayme Abrey - as a technician of the INEP about the secondary education; on the other side, it analyzes the prescriptions of the Secondary Education Directory of the Ministry of Education and Culture to the experimental secondary classes. In a era marked by fierce educational debates, we attempt to give visibility to the renewing pedagogical model of the secondary Brazilian education, that was opposed the Capanema Reform.

Keywords: Seconday Education. Movement of Pedagogical Renewal. INEP. 


\section{Norberto Dallabrida}

E-mail: norbertodallabrida@gmail.com

Recebido em: 30/2/2014

Versáo final recebida em: 16/4/2014

Aprovado em: 22/4/2014 